\section{Commentary: Reversing the irreversible ischemic fibrosis with extracellular vesicle therapy}

\author{
Alyssa D. Murillo, MD, MS, ${ }^{\mathrm{a}}$ and \\ Tom C. Nguyen, $\mathrm{MD}^{\mathrm{b}}$
}

Sellke and colleagues ${ }^{1}$ should be congratulated for investigating the role of extracellular vesicles (EVs) in improving diastolic dysfunction and myocardial fibrosis across normal and high-fat diet animal models with chronic myocardial ischemia.

The present article used a validated animal model that employed an ameroid constrictor that slowly occludes the left circumflex artery over 2 weeks to generate a model of chronic ischemia followed by 8 injections of saline or EVs. ${ }^{2,3}$ The authors describe EVs as lipid-enclosed particles containing vast protein, RNA, and lipid content that are capable of modulating diverse pathways while avoiding the risk of tumorigenicity and immunogenicity. The pigs were then exposed to a normal or high-fat diet validated to produce clinical characteristics of metabolic syndrome, hypertension, dyslipidemia, and impaired glucose tolerance. ${ }^{4}$ The authors concluded that injections of EVs improved diastolic function, and reduced perivascular fibrosis, mineralization, and hypertrophy in normal and high-fat diet swine. Their results suggest a potential novel treatment in the previously irreversible fibrosis and cell death described in chronic ischemic heart disease and subsequent heart failure.

Ischemic heart disease is a leading cause of death worldwide with chronic ischemic insult leading to irreversible injury characterized by loss of cardiomyocytes and formation of fibrotic scar. ${ }^{5}$ In the context of cardiovascular disease, EVs have displayed proangiogenic, immunosuppressive, and antioxidant properties, ${ }^{6,7}$ with this study now demonstrating

\footnotetext{
From the ${ }^{\mathrm{a} D e p a r t m e n t}$ of Surgery and ${ }^{\mathrm{b}}$ Division of Cardiothoracic Surgery, Department of Surgery, University of California, San Francisco, Calif.

Disclosures: The authors reported no conflicts of interest.

The Journal policy requires editors and reviewers to disclose conflicts of interest and to decline handling or reviewing manuscripts for which they may have a conflict of interest. The editors and reviewers of this article have no conflicts of interest.

Received for publication Aug 7, 2021; revisions received Aug 7, 2021; accepted for publication Aug 9, 2021; available ahead of print Aug 13, 2021.

Address for reprints: Tom C. Nguyen, MD, Division of Cardiothoracic Surgery, Department of Surgery, University of California, San Francisco, 505 Parnassus Ave, San Francisco, CA 94143 (E-mail: tom.c.nguyen@gmail.com).

J Thorac Cardiovasc Surg 2022;164:e385-6

$0022-5223 / \$ 36.00$

Copyright (C) 2021 by The American Association for Thoracic Surgery

https://doi.org/10.1016/j.jtcvs.2021.08.016
}

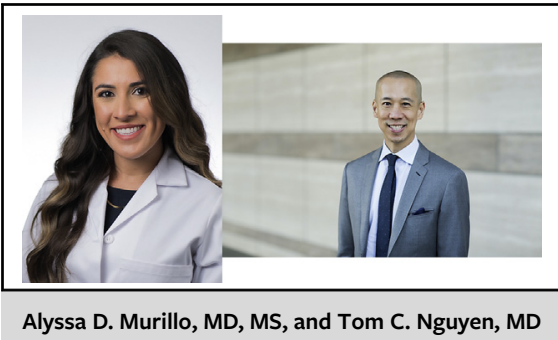

CENTRAL MESSAGE

Extracellular vesicle therapy

improved the myocardium's

ability to relax across both

normal and high-fat diet animal

models of chronic myocardial

ischemia.

antifibrotic effects. ${ }^{1}$ The authors should be applauded on their eloquent experiments; however, we question the feasibility and translatability to clinical practice. The relatively young age of the animal models at intervention (11 weeks), short course of diet modification (16 weeks), and inability to replicate the complexities of adult diseases will require further studies to bring EVs to clinical practice. As well, the route and timing of EV administration in clinical practice remains obscure. Future studies could compare injections to catheter infusions both as standalone interventions or at the time of revascularization procedures such as coronary artery bypass grafting or percutaneous coronary interventions.

The authors pose a compelling discussion regarding the implications of their findings in the management of heart failure with preserved ejection fraction (HFpEF) defined by impaired relaxation of the myocardium secondary to fibrosis with elevated end diastolic pressures. There currently exists no targeted therapy for HFpEF despite the prevalence being as high as $30 \%$ of the general population. ${ }^{8}$ This study demonstrated improved end diastolic pressure volume relationship through extrapolation of pressurevolume loops as markers of diastolic dysfunction. To further validate clinical significance, the authors could have considered evaluation with cardiac magnetic resonance imaging or echocardiography, both of which are hallmarks of HFpEF diagnosis. As well, pressure-volume loops evaluate global cardiac function, whereas imaging would allow focused visualization of the ischemic region increasing the specificity of their assessment. 
This article represents an exciting new future for a worldwide disease that has no curative treatment or targeted therapy capable of reversing or halting progression of the inciting pathology. ${ }^{9}$ Is it possible that an ischemic heart could heal itself if we just provide the right supplies? Time will tell, but this study by Selke and colleagues ${ }^{1}$ suggests that fibrosis from ischemic heart disease has the potential to be reversed.

\section{References}

1. Aboulgheit AM, Karbasiafshar C, Sabra M, Zhang Z, Sodha N, Abid MR, Sellke F. Extracellular vesicles improve diastolic function and substructure in normal and high-fat diet models of chronic myocardial ischemia. J Thorac Cardiovasc Surg. 2022;164:e371-84.

2. Aboulgheit A, Potz BA, Scrimgeour LA, Karbasiafshar C, Shi G, Zhang Z, et al. Effects of high fat versus normal diet on extracellular vesicle-induced angiogenesis in a swine model of chronic myocardial ischemia. J Am Heart Assoc. 2021;10: e017437.

3. Scrimgeour LA, Potz BA, Aboul Gheit A, Shi G, Stanley M, Zhang Z, et al. Extracellular vesicles promote arteriogenesis in chronically ischemic myocardium in the setting of metabolic syndrome. J Am Heart Assoc. 2019;8:1-14.

4. Zhang X, Lerman LO. Investigating the metabolic syndrome: contributions of swine models. Toxicol Pathol. 2016;44:358-66.

5. Roth GA, Johnson C, Abajobir A, Abd-Allah F, Abera SF, Abyu G, et al. Global, regional, and national burden of cardiovascular diseases for 10 causes, 1990 to 2015. J Am Coll Cardiol. 2017;70:1-25.

6. Davidson SM, Yellon DM. Exosomes and cardioprotection-a critical analysis. Mol Aspects Med. 2018;60:104-14.

7. Karbasiafshar C, Sellke FW, Abid MR. Mesenchymal stem cell-derived extracellular vesicles in the failing heart: past, present, and future. Am J Physiol Circ Physiol. 2021;320:H1999-2010.

8. Kuznetsova T, Herbots L, López B, Jin Y, Richart T, Thijs L, et al. Prevalence of left ventricular diastolic dysfunction in a general population. Circ Heart Fail. 2009;2:105-12.

9. Mandinov L, Eberli FR, Seiler C, Hess OM. Diastolic heart failure. Cardiovasc Res. 2000;45:813-25.

\section{Commentary: Cell therapy goes subcellular}

\author{
Vaibhav B. Patel, $\mathrm{PhD},{ }^{\mathrm{a}, \mathrm{b}}$ and \\ Paul W. M. Fedak, MD, PhD, FRCSC ${ }^{\text {,c }}$
}

Maladaptive structural cardiac remodeling and resultant clinical heart failure associated with ischemic heart disease is a global burden on health care systems. Contemporary pharmacologic therapies combined with surgical revascularization improves patient survival but fails to prevent fibrotic scar formation and replace lost cardiomyocytes. ${ }^{1}$ Stem cell therapy repopulates damaged myocardium and offers the promise of replacing lost contractile elements to restore function and prevent heart failure. However, the benefits of cell-based therapies shown in animal models are poorly translated when applied to human patients. Enthusiasm for cell clinical cardiovascular therapy is

From the ${ }^{\mathrm{a} D e p a r t m e n t ~ o f ~ P h y s i o l o g y ~ a n d ~ P h a r m a c o l o g y, ~ a n d ~}{ }^{\mathrm{c}}$ Section of Cardiac Surgery, Department of Cardiac Sciences, Cumming School of Medicine, and ${ }^{\mathrm{b}}$ Libin Cardiovascular Institute, University of Calgary, Calgary, Alberta, Canada.

Disclosures: The authors reported no conflicts of interest.

The Journal policy requires editors and reviewers to disclose conflicts of interest and to decline handling or reviewing manuscripts for which they may have a conflict of interest. The editors and reviewers of this article have no conflicts of interest.

Received for publication Sept 7, 2021; revisions received Sept 7, 2021; accepted for publication Sept 7, 2021; available ahead of print Sept 9, 2021.

Address for reprints: Paul W. M. Fedak, MD, PhD, FRCSC, C849, 1403-29 St NW, Calgary, Alberta, Canada T2N 2T9 (E-mail: paul.fedak@gmail.com).

J Thorac Cardiovasc Surg 2022;164:e386-7

$0022-5223 / \$ 36.00$

Copyright (c) 2021 by The American Association for Thoracic Surgery

https://doi.org/10.1016/j.jtcvs.2021.09.004

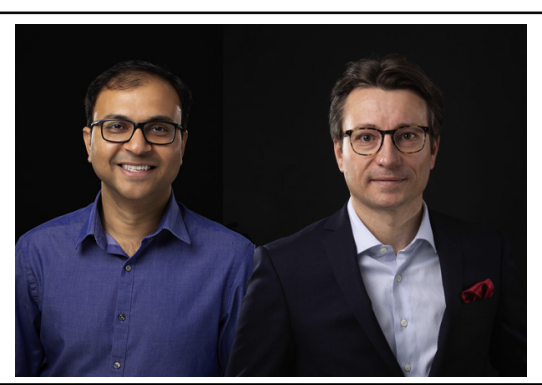

Vaibhav B. Patel, PhD, and Paul W. M. Fedak, MD, PhD, FRCSC

CENTRAL MESSAGE

Extracellular vesicle-based thera-

peutics show potent cardiopro-

tection in a clinically relevant and

unique large animal model of

chronic ischemic heart disease

with diastolic dysfunction.

tempered by numerous translational barriers such as poor survival of the engrafted cells, induction of arrhythmias, and allorejection. ${ }^{2}$ Paracrine mediators released by stem cells are increasingly recognized to drive the beneficial effects of cell therapies, suggesting that the cells themselves may not be necessary to achieve novel subcellular-based therapies. $^{3}$

Extracellular vesicles (EVs) are a heterogeneous group of lipid-bound particles produced and secreted by various 